\title{
DA DIMENSÃO HISTÓRICA NA ANÁLISE DE ESTILO EM OBRAS DE ARTE: CONTRIBUICCÕES DE BOURDIEU
}

\section{FROM THE HISTORICAL DIMENSION IN THE ANALYSIS OF STYLE IN WORKS OF ART: CONTRIBUTIONS BY BOURDIEU}

Morgana Gama de Lima ${ }^{1}$ 


\section{Resumo}

Tendo em vista a importância e a centralidade que a figura do autor ou agente realizador apresenta em estudos relacionados à investigação de questões de estilo em obras de arte, esse artigo pretende refletir como a dimensão histórica contribui no exercício interpretativo de produções culturais. Como parte de nosso percurso reflexivo, apresentamos inicialmente algumas abordagens desenvolvidas por Ernst H. Gombrich (1984; 2005), no que se refere a questões de estilo, para, posteriormente, discutir de forma mais ampla os desdobramentos dessa perspectiva histórica através da argumentação de Pierre Bourdieu em seu livro As regras da arte (2002).

Palavras-chave: Estilo. História da arte. Pierre Bourdieu.

\section{Abstract}

Considering the importance and the centrality that the figure of the author or agent presents in Studies related to the investigation of questions of style in works of art, this article aims to reflect on how the historical dimension contributes for the interpretative exercise of cultural productions. As part of our reflection, firstly we present some approaches developed by Ernst H. Gombrich (1984; 2005) in terms of style issues, to later discuss more broadly the unfolding of this historical perspective through Pierre Bourdieus's auguments in his book The rules of art (2002).

Keywords: Style. History of art. Pierre Bourdieu.

ISSN: 2175-2346 
Não há nada para além da história Pierre Bourdieu ${ }^{1}$

\section{Da questão de estilo}

De acordo com o historiador da arte Ernst H. Gombrich (1984), a origem da palavra estilo está relacionada à palavra stillo, instrumento de escrita utilizado pelos romanos, e que acabou se tornando uma referência à capacidade de expressão e persuasão, tanto na fala quanto na escrita. Para além da questão nominal - que por si já dava indícios de uma preocupação com a técnica - a questão do estilo só vai se aproximar do universo das artes plásticas, e depois de outras expressões artísticas, a partir de metáforas, empregadas por Quintiliano, ao comparar o progresso da oratória latina com próprio progresso da história da arte.

Por essa influência das artes plásticas no que tange à discussão de técnicas relacionada à questão de estilo, a interpretação da obra de arte - e aqui, sobretudo, a pictórica - terá como um de seus parâmetros de avaliação a busca por uma reprodução fidedigna do mundo. Em contraposição a essa tendência, alguns historiadores como o alemão Adolf von Hildebrand, ao tratar do problema da forma na arte figurativa, irá se opor aos ideais do naturalismo científico e argumentar que se tentarmos analisar nossas imagens mentais para descobrir os seus principais constituintes, descobriremos que consistem em dados sensoriais derivados da visão e de memórias de toque e movimento. Assim, se tais percepções estão longe de ser uma representação fidedigna, muito menos o seriam a crítica ou a interpretação acerca de uma obra.

Como herdeiro desse pensamento, Alois Riegl vai associar as ideias de Hildebrand com o estudo da evolução artística, eliminando o valor subjetivo da história da arte com o fim de torná-la uma ciência respeitável. E é a partir daí que a diferença de estilo nas obras de arte passa a ser associada a mudanças de intenção: longe de serem resultado de uma reação às circunstâncias, elas (as mudanças) expressariam uma reorientação geral das intenções artísticas. Nessa nova perspectiva, a função do historiador da arte não era apenas julgar, mas explicar, contribuir com a compreensão da obra em suas intenções.

Como parte dos métodos para empreender a análise de estilo, conhecer a tecnologia empregada na produção da obra de arte, as tradições vigentes na época, bem como, a formação e biografia do agente realizador se tornaram informações importantes. A grande dificuldade, porém que se percebe nesse percurso trilhado por diferentes teóricos e historiadores da arte está em articular essa intenção pressuposta no ato criativo - um aspecto subjetivo - a outros elementos objetivos, relacionados à técnica utilizada no fazer artístico e do próprio contexto no qual o artista (agente) está inserido. Diante dessa dificuldade em equacionar aspectos subjetivos e objetivos do ato criativo, não é raro encontrar trabalhos de investigação e crítica de obras de arte baseados apenas em métodos cuja ênfase recai nos aspectos técnicos envolvidos na criação ou, ainda, restritos à figura do agente que realiza a obra. Mesmo que ambos os métodos contribuam para o processo interpretativo, eles estão sujeitos ao risco de 
produzir uma compreensão incompleta e tendenciosa, ora sobrepondo à técnica ao agente realizador, subsumindo toda a autonomia criativa do artista, ora enaltecendo o agente criador, em detrimento de todo o histórico de produções artísticas que influenciaram na sua formação e processo de criação.

Tendo em vista a predominância desse dilema, daremos destaque às contribuições apresentadas por Pierre Bourdieu no livro As regras da arte (2002), justamente pela articulação que sua abordagem propõe entre a obra de arte e as circunstâncias que perpassam o seu ato da criação, logo, uma abordagem que torna possível avaliar o objeto, considerando também o agente responsável pela sua criação, aproximando-o do contexto no qual ele está inserido. Uma aproximação delicada, visto que pode resultar em uma manobra científica arriscada (ou até contraditória), quando a referência ao contexto ofusca as propriedades do objeto ou, inversamente, quando a ênfase no objeto desconsidera os fatores sociais do seu entorno. Como lidar com essa dualidade? Como compreender o processo criativo, tão ligado ao agente, logo imbricado em questões subjetivas e, ao mesmo tempo, avaliar as circunstâncias sociais na qual essa criação emerge?

O impasse entre objetividade e subjetividade que atravessa as discussões relacionadas aos métodos de análise e investigação de questões de estilo em obras de arte, acaba sendo um desdobramento de um conflito que perpassa diversas correntes teóricas das Ciências Humanas, incluindo o campo da Sociologia, de modo geral, e também a Sociologia da Cultura. Bourdieu, pela sua trajetória acadêmica, e em virtude dos seus interesses de pesquisa acaba trazendo, através de seus conceitos, ferramentas teórico-metodológicas que podem ajudar ao analista, crítico ou historiador de arte a lidar com esses impasses a partir de uma perspectiva que, relacionando agente e história, incorpora as relações de poder, como parte da dinâmica da criação, contribuindo para uma compreensão mais complexa e socialmente integrada da obra de arte.

\section{A distinção entre estilo e autoria}

Segundo o professor Dr. Benjamin Picado² a questão do estilo, em obras de arte, pode ser caracterizada como medium da gestão intencional (de quem realiza), designando marcas de redundância nas obras. É a presença da intenção que caracteriza o fazer artístico. Para esclarecer, o professor comenta um exemplo do livro $A$ pintura como arte $^{3}$, de Richard Wollheim, em que o historiador ressalta que a diferença entre o pintor de parede e o pintor de murais está na intenção de quem executa. Sendo assim, apesar da existência de um sujeito estar pressuposta pela existência de uma intenção, a definição de estilo nas obras de arte implica mais em um ato interpretativo sobre a obra, identificação de determinadas marcas, do que, necessariamente, a sua dependência ou associação a um sujeito. Embora o agente, o artista, seja um elemento importante para compreender a questão do estilo, sobretudo, quando se parte da concepção de que ele é responsável pelas decisões e escolhas que definem

2 Professor da Universidade Federal Fluminense (UFF), convidado para palestra na aula inaugural da disciplina Temas Especiais em Metodologias de Análise de Produtos e Linguagens da Cultura Mediática, do Programa de Pós-Graduação em Comunicação e Cultura Contemporâneas, da Universidade Federal da Bahia, realizada no dia 07 de julho de 2016, via Skype, e sob a mediação da Prof. Dra. Maria Carmen Jacob.

3

Título original do livro: Painting as an art (1987). 
a obra em sua forma final, a presença de estilo entre as obras de um realizador se define mais pela contiguidade, afinidade de umas com as outras, do que, necessariamente, pelo seu pertencimento a um mesmo realizador.

Em outro escrito sobre o exercício interpretativo de obras de arte, Gombrich (2005) argumenta que a evolução das ideias de estilo também está relacionada a uma compreensão da história da representação no campo da arte. Foi pelo viés da representação que a criação artística passou a ser compreendida como ilusão e a investigação relacionada ao estilo foi progressivamente confundida com os estudos de psicologia da percepção. Como o próprio historiador assume: "Recorri frequentemente à psicologia a fim de buscar uma explicação para certos fenômenos que se manifestaram na história da representação pictórica." (GOMBRICH, 2005, p. 18).

Essa tentativa de buscar explicações para as diferenças de estilo a partir dos estudos da psicologia dedicados à percepção acaba direcionando a um percurso de análise de retorno para o sujeito. Contudo, ao visitar outras referências relacionadas à questão de estilo na obra de arte, percebe-se que essa perspectiva tem limitações na medida em que relega a segundo plano fatores circunstanciais que estão para além do agente criador tais como o próprio contexto sociocultural no qual ele está inserido e a influência deste na constituição da percepção do agente.

Embora tais fatores de ordem contextual, de alguma forma, tenham se feito presentes ao longo das investigações e análises de produções artísticas, Gombrich dá a entender que nem sempre essas informações históricas foram aproveitadas de forma a contribuir para uma interpretação e compreensão das obras:

A história do gosto e da moda é a história das preferências, de vários atos de escolha entre alternativas dadas. [...] Tais mudanças no estilo e no prestígio dos estilos podem ser descritas (embora exaustivamente) em termos de uma "vontade de formar"; ninguém duvida que eles eram sintomáticos de um conjunto de atitudes. Mas o que importa aqui, do ponto de vista do método, é que um ato de escolha é apenas de significado sintomático, é expressivo de algo apenas se nós pudermos reconstruir a situação de escolha (GOMBRICH, 2005, p. 16, grifo nosso).

Desta forma, embora Gombrich, enquanto historiador, não tenha desenvolvido um método preciso que permitisse reconstruir a situação na qual se dá a escolha, já havia em seu pensamento a sensibilidade para perceber a importância em se compreender o contexto no qual o artista ou agente estava inserido, através dessa reconstituição, entender as escolhas possíveis para o autor. Citando o seu mentor Ernst Kris, Gombrich também destaca:

Há muito que nos damos conta de que a arte não é produzida em um espaço vazio, nenhum artista é independente de predecessores e modelos, que ele não menos do que o cientista e o filósofo é parte de uma tradição específica e trabalha em uma área estruturada de problemas. O grau de domínio neste quadro e, pelo menos em certos períodos, a liberdade de modificar estas restrições são presumivelmente parte da escala complexa pela qual a realização está sendo medida (KRIS, apud GOMBRICH, 1984, p. 23, tradução e grifo nossos) $)^{4}$.

\footnotetext{
4 Do original: We have long come to realize that art is not produced in an empty space, that no artist is independent of predecessors and models, that he no less than the scientist and the philosopher is part of a specific tradition and works in a structured area of problems. The degree of mastery within this framework and, at least in certain periods, the freedom to modify these stringencies are presumably part of the complex scale by which achievement is being measured.
} 
Como parte de sua preocupação em demonstrar que o artista é parte de um contexto ("nenhum artista é independente de predecessores e modelos"), Gombrich, ao longo de suas argumentações, vai tentar reconstruir a situação na qual se deu a escolha, a partir da referência a escolas e tradições vigentes na época de realização da obra. Uma articulação válida, mas que tinha suas limitações pela possibilidade de induzir o pensamento interpretativo a outro extremo, ou seja, o de que tais estruturas formativas e convenções se sobrepunham ao ato criativo individual, anulando a autonomia criativa do artista. Como forma de refutar essa hipótese, Gombrich também deixou claro em seus escritos que "as instituições artesanais, com suas tradições estritas e perfeitamente regradas, nem sempre impediram a criatividade" (GOMBRICH, 1990, p. 37).

No que se refere à interação do agente com as tradições/ convenções, a noção de espaço dos possíveis apresentada por Pierre Bourdieu (2002) traz alguns esclarecimentos. Segundo ele, o espaço dos possíveis é um sistema historicamente datado e situado de esquemas de percepção, apreciação e expressão e pode ser encontrado tanto nas coisas (nas próprias obras, por exemplo), quanto em estado incorporado nas estruturas mentais e nas disposições do agente (saberes, técnicas, habilidades, etc.). Com isso, ele demonstra como as tradições operavam simultaneamente tanto em favor do sistema objetivo que as haviam gerado, quanto em favor do próprio agente que deseja inserir-se no sistema.

Além de atentar para o contexto e a influência exercida por essas instituições e tradições - questão que Bourdieu irá aprofundar e desenvolver - outro ponto de convergência entre esses dois autores é a busca por um rigor científico na análise de obras culturais.

\section{Por um olhar científico nas artes}

Como parte da busca por rigor científico na análise de obras artísticas, as competências de interpretar e explicar acabam sendo atribuídas ao historiador da arte; contudo, as ferramentas ou habilidades de que ele dispõe podem ser tendenciosas ou insuficientes. Assim, mesmo que o historiador não tenha garantias acerca da legitimidade de sua interpretação acerca da obra, ele deve ter a capacidade de produzir algo que permita às pessoas entenderem os principais elementos que concernem à criação da obra para além do sujeito que a criou. As informações técnicas e o conhecimento acerca das tradições artísticas são importantes, contudo, como já foi mencionado, devem ser articuladas a outros aspectos que sustentem a possibilidade de reconstrução da situação histórica em que se deram as escolhas apresentadas na obra e aquilo que as mesmas podem significar.

Apesar da consideração do elemento histórico parecer ser algo meio óbvio no processo de análise de um fenômeno ou objeto do campo da produção artístico-cultural pouco se discute acerca das metodologias a serem empregadas a fim de incorporar esse elemento ao percurso de análise. Discussão que, ao ser adiada, pode implicar no desenho de duas vertentes de análise: aquelas que supervalorizam o contexto em detrimento das particularidades e propriedades do fenômeno, correndo o risco de fazer projeções sobre o objeto ao partirem de uma ideia muito ampla e 
generalista da situação na qual ele se constrói. O contrário também pode ocorrer, quando, em favor da compreensão do objeto, se desconsidera ou se deixa de investigar as circunstâncias que contornam sua existência enquanto fenômeno.

Nesse sentido, Pierre Bourdieu contribui de forma significativa para a análise de produções na cultura por formular princípios que permitem contornar essa aparente dualidade de perspectiva nas ciências sociais e na sociologia da cultura, de modo particular. Tais princípios irão influenciar no seu repertório conceitual e, consequentemente na construção de sua proposta metodológica. Assim, mais do que compreender o sentido de seus conceitos, é necessário compreender como essa dualidade contornava o contexto de emergência de suas ideias e como o seu legado teórico pode contribuir, ainda nos dias de hoje, enquanto potente proposta metodológica para lidar com os impasses e desafios da investigação da questão de estilo.

Nos estudos de Sociologia, por exemplo, a discussão acerca dos métodos epistemológicos oscila entre dois pólos: subjetivismo (estudos que partem da experiência do indivíduo, associado ao que veio se denominar de fenomenologia) e objetivismo (perspectiva em que as relações objetivas estruturam as práticas). Segundo Alicia Gutiérrez, em seu artigo Análisis y acción: notas sobre Pierre Bourdieu (2002), Bourdieu, em sua forma de pensamento, tenta superar a "falsa" dicotomia entre as posições objetivistas e subjetivistas nas investigações das ciências sociais. Para ele, as duas formas de abordar a realidade social são parciais: o modo de pensamento objetivista resgata as relações objetivas que condicionam as práticas (o sentido objetivo), mas não dá conta do sentido vivido pelas mesmas, nem da dialética que se estabelece entre objetivo e subjetivo. Já o modo de pensamento subjetivista considera o sentido vivido das práticas, percepções e representações dos agentes, o que pensam e sentem, sem considerar, no entanto, as condições sociais e econômicas que constituem o fundamento de suas experiências. Como se pode perceber, o problema dessas duas vertentes é que elas concedem um espaço bem delimitado para a experiência, em outros termos, à vontade do agente social.

Como saída a tal impasse, Bourdieu (1972) adota o chamado conhecimento praxiológico em que propõe uma articulação dialética entre o ator social (subjetivo) e a estrutura social (objetivo) ${ }^{5}$, cujo foco de investigação não seria somente o sistema de relações objetivas, mas também as relações dialéticas entre as estruturas objetivas e as "disposições estruturadas" nas quais essas estruturas se atualizam e tendem a se reproduzir. E aqui por disposições estruturadas, iremos entender adiante que ele está se referindo às disposições (habitus) do próprio agente que, embora enquanto sujeito seja um elemento independente da estrutura, ao se relacionar com ela, está passível de atualizar e reproduzir a lógica que a mantém através de suas práticas.

Já no âmbito de estudos da Sociologia da Cultura, a discussão girava em torno de outro impasse, dessa vez, relacionada à forma como a cultura, enquanto sistema de fatos e representações (incluindo sistemas simbólicos, mitos, linguagens), deveria ser compreendido. De um lado, uma das vertentes entendia a cultura como instrumento de comunicação e conhecimento e, por isso, responsável pelo consenso (no

$5 \quad$ Renato Ortiz (1983) também explica essa dialética nos seguintes termos: "A problemática teórica dos escritos de Bourdieu repousa essencialmente sobre a questão da mediação entre o agente social e a sociedade" (ORTIZ, 1983, p. 8, grifo nosso). 
sentido de buscar um acordo quanto ao significado dos signos). Já a outra vertente partia da compreensão de que a cultura era um instrumento de poder responsável pela legitimação da ordem vigente.

Sérgio Miceli, em prefácio à edição brasileira do livro $A$ economia das trocas simbólicas (BOURDIEU, 1999), esclarece que Bourdieu dialoga com tradição mais estruturalista (a primeira vertente) na medida em que seus instrumentos teóricos e metodológicos contribuem para descobrir a lógica imanente de um bem simbólico. Bourdieu, porém, criticaria uma de suas correntes teóricas (a semiologia, escola linguística desenvolvida por Ferdinand Saussure), por esta querer aplicar a teoria do consenso a qualquer objeto. Em sua análise estrutural, antagônica a uma teoria social, Saussure compreendia o agente social como mero executor de algo que the é externo e se encontra objetivamente programado (o sistema linguístico), privilegiando assim as funções de comunicação/conhecimento da língua, desconsiderando as diferenças entre aqueles que executam a língua. $\mathrm{Na}$ interpretação de Bourdieu, essa concepção poderia redundar em um etnocentrismo, pois tratar das funções de comunicação em detrimento de suas potenciais funções políticas e econômicas seria partir do pressuposto de uma coincidência total entre os agentes envolvidos na interação, o que anularia a diferença entre eles. É assim que, para além da "função comunicativa" das práticas culturais (considerando as obras de arte como parte disso), os estudos de Bourdieu vão privilegiar as "funções sociais"6 dessas práticas.

Por entender a necessidade de considerar essa função social, é que Bourdieu vai agregar a contribuição de autores como Marx, Weber e Durkheim com o fim de:

[...] retificar a teoria do consenso por uma concepção teórica capaz de revelar condições materiais e institucionais que presidem à criação e à transformação de aparelhos de produção simbólica cujos bens deixam de ser vistos como meros instrumentos de comunicação e conhecimento (BOURDIEU, 1999, p. XII).

Essa é uma das vias pela qual Bourdieu vai construir o lastro teórico necessário para compreender o funcionamento dessas diferenças no interior dos sistemas simbólicos (cultura) e apresentar uma proposta de ciência das obras culturais que tem por pressuposto essa concepção de que tanto a produção das obras, quanto à interação entre $o$ agente social e a sociedade, ocorre dentro de um processo historicamente dado e construído, como é possível apreender no seguinte fragmento:

De fato, todo o meu empreendimento científico se inspira na convicção de que não podemos capturar a lógica mais profunda do mundo social a não ser submergindo na particularidade de uma realidade empírica, historicamente situada e datada, para construí-la, porém, como "caso particular do possível", conforme a expressão de Gaston Bachelard, isto é, como uma figura em um universo de configurações possíveis (BOURDIEU, 1996, p. 15, grifo nosso) ${ }^{7}$.

\footnotetext{
6 Funções que podem se transformar em funções políticas também na medida em que a lógica de ordenação do mundo subordina-se às funções de diferenciação social e legitimação das diferenças. Cf. BOURDIEU, 1999.

7 Sobre "espaço social" mencionado em sua obra La distinction, extraído do livro Razões práticas (BOURDIEU, 1996, p. 15).
} 
Por esse princípio já é possível perceber a preocupação de Bourdieu (1996) em situar historicamente determinada realidade, de modo a capturar o que ele entende ser a lógica mais profunda do mundo social. É nesses termos que a denominada Sociologia dos Sistemas Simbólicos, de Bourdieu, vai se opor tanto àqueles que interpretavam os fenômenos simbólicos como parte da Sociologia do Conhecimento quanto aos que acreditavam se tratar de uma Sociologia do Poder. Pela sua Sociologia, Bourdieu pretendia entender os princípios que sustentavam a eficácia própria dos símbolos e que lhes conferia poder externo (político). As questões que se colocam a partir daí são: como esses princípios podem ser identificados? Como o conhecimento histórico contribui nesse sentido?

Apesar de o agente ter "liberdade" para fazer determinadas escolhas, essa liberdade é limitada por condições socialmente estabelecidas às quais, por sua vez, são resultantes de relações históricas e sociais:

Ao afirmar que a 'verdade de um fenômeno cultural depende do sistema de relações históricas e sociais nos quais ele se insere' [...], pretende exorcizar os perigos em que incorre a explicação transistórica ou transcultural cujo apego aos traços constantes perde de vista sua especificidade histórica ou sua originalidade cultural (BOURDIEU, 1999, p. XXIX).

Assim, o exame e a investigação de questões relacionadas ao estilo, embora tenham a obra de arte como pontos de partida não podem negligenciar o caráter histórico de que ela é portadora e veículo. É pela preocupação com essas relações, dadas historicamente, que Bourdieu inova ao introduzir nas relações de interação a questão do poder, até então negligenciado por algumas escolas do interacionismo simbólico ${ }^{8}$. Uma perspectiva teórica que objetiva:

[...] retificar a teoria do consenso por uma concepção teórica capaz de revelar condições materiais e institucionais que presidem à criação e à transformação de aparelhos de produção simbólica cujos bens deixam de ser vistos como meros instrumentos de comunicação e ou conhecimento (BOURDIEU, 1999, p. XII)9.

Enquanto Foucault está interessado no modo pelo qual o poder se exerce por meio de performances e discursos, Bourdieu entende que o discurso não só não provoca a ação, como não a explica. Assim, ele busca, no campo das divergências de interesses ou hábitos mentais entre indivíduos, o princípio explicativo daquilo que acontece no "campo das possibilidades" estratégicas. Bourdieu define a partir daí um novo conceito de poder, o poder simbólico, um poder invisível o qual só pode ser exercido com a cumplicidade daqueles que não querem saber que lhes estão sujeitos ou mesmo que o exercem.

A questão, portanto, é encontrar a mediação entre o agente social, a sociedade, o homem, e a história. Para isso, Bourdieu se apropria da noção de habitus, até então

$8 \quad$ Ainda que Bourdieu traga semelhanças com o Interacionismo Simbólico - desenvolvido por pesquisadores como Erving Goffman a partir da dramaturgia teatral - por reabilitar a ação do ator social nos estudos de sociologia, há um ponto de divergência: para o Interacionismo, o agente tem a possibilidade de definir uma dada situação (micro-sociologia), enquanto para Bourdieu não há essa possibilidade de intervenção do ator sobre a situação, pois a interação é objetivamente estruturada (macro-sociologia). Cf. ORTIZ, 1983, p. 25. 
usada no contexto da escolástica no sentido de enfatizar um aprendizado passado, e que é reinterpretada por ele como um "sistema de disposições duráveis". Em parte, essa noção dialoga diretamente com aquilo que foi uma das maiores preocupações de Gombrich nas suas investigações acerca do estilo: as tradições, estilos e escolas artísticas. Segundo o historiador, é por meio dessas convenções que emerge o que ele denominou de "segunda natureza", uma espécie de conhecimento adquirido pelo agente que vai além do saber teórico das tradições artesanais, mas implica em uma "sensibilidade material frente aos problemas" (GOMBRICH, 1999, p. 37). Apesar de Gombrich perceber que a relação do agente com as convenções ia além da mera cópia ou reprodução, acionando uma espécie de nova "sensibilidade" no agente, a sua perspectiva de compreensão de estilo estava muito arraigada ao sujeito (no âmbito da criação) e a questão de percepção (no âmbito da recepção/ interpretação) razão pela qual, chega a sugerir que essa segunda natureza fosse objeto de investigação dos psicólogos.

Com a noção de habitus ${ }^{10}$, Bourdieu (2002), ao tempo em que remete à ideia de "aprendizado passado", também põe em pauta a influência que a estrutura social vai exercer nesse processo, pois o "processo de interiorização [pelo indivíduo] implica sempre internalização da objetividade, o que ocorre certamente de forma subjetiva, mas que não pertence exclusivamente ao domínio da individualidade" (ORTIZ, 1983, p. 17). É por esse conceito que Bourdieu promove a integração e a mediação, entre duas instâncias que pareciam divergentes - o subjetivo e o objetivo. Através do habitus, o agente (subjetivo) interioriza normas, valores e princípios, os quais, por sua vez, promovem o ajuste das ações do agente ao sistema e contribuem para a manutenção desse mesmo sistema (objetivo).

\section{Contribuições de As regras da arte}

Após discutir algumas questões relacionadas à importância de elementos históricos no processo de investigação de estilo, primeiramente no contexto da História da Arte, com Gombrich, depois com a compreensão da sociologia de Bourdieu e a sua noção de habitus, nesta seção, vamos nos reportar de forma específica a alguns conceitos apresentados no livro As regras da arte que podem ser úteis para a organização de um percurso metodológico de análise de estilo. Através de conceitos como habitus, posição/disposição/tomada de posição e trajetória construída, é possível perceber como Bourdieu estabelece relações com o elemento histórico. Relações que enfatizam a importância de considerar a questão do estilo a partir de um sujeito situado em um dado momento da história. Acreditamos que, por essa perspectiva, seja possível delinear alguns parâmetros a partir dos quais a mediação agente social-sociedade seja observada e, ao mesmo tempo, percebida como uma relação marcada por relações de poder, negociações e disputas, visto que tem por "pano de fundo" a distribuição desigual de bens simbólicos.

10 Outra forma que o autor define o habitus é como "estruturas estruturadas predispostas a funcionarem como estruturas estruturantes" (BOURDIEU, apud ORTIZ, 1983, p. 17). Um trocadilho que evidencia o caráter relacional e dialético do pensamento sociológico de Bourdieu. 
Ao tratar sobre a biografia do agente, Bourdieu formula o conceito de trajetória construída (BOURDIEU, 2002, p. 292). Tal conceito envolve entender que, embora as escolhas sobre a obra sejam provenientes de escolhas do sujeito (agente), elas estão sintonizadas com as condições objetivas do contexto. Segundo Bourdieu, não podemos entender a obra centrando a análise apenas na trajetória realizada pelo agente, visto que é preciso considerar a rede de possibilidades objetivas que estavam à sua disposição durante o percurso criativo. Uma forma de compreender visualmente essa noção de trajetória pode ser vista no gráfico da Figura 1:

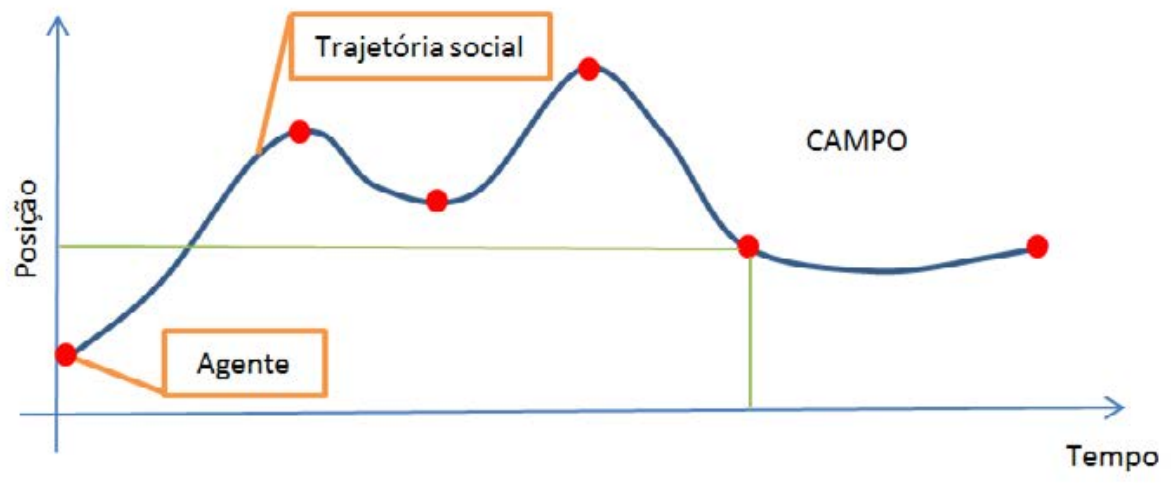

Fig. 1 - Ilustração de "Trajetória Construída" segundo conceito de Pierre Bourdieu.

Cada posição ocupada pelo ponto vermelho no gráfico corresponde a um "acontecimento biográfico" que "posiciona" o agente no interior do campo sendo sucessivamente ocupadas (ou seja, uma após a outra). Os pontos elevados podem ser considerados como momentos de "sucesso", em contraste com os pontos mais baixos ("fracassos"); unindo um ponto ao outro, a linha azul dá forma à trajetória construída pelo agente dentro do campo. Constituiria-se assim uma trajetória que se desenvolve a partir de variáveis subjetivas (o agente, o habitus, etc.) e objetivas (o estado campo, os códigos, regras, etc.). Trata-se, obviamente, de uma ilustração deveras simples para a complexidade do conceito (que envolve outras variáveis); no entanto, a proposta é ratificar a definição apresentada por Bourdieu:

Toda trajetória deve ser compreendida como uma maneira singular de percorrer o espaço social, onde se exprimem as disposições do habitus, cada deslocamento para uma nova posição, enquanto implica a exclusão de um conjunto mais ou menos vasto de posições substituíveis [...] marca uma etapa de "envelhecimento social" (2002, p. 292, grifo nosso).

Para uma leitura adequada da análise da relação entre posições sociais (conceito relacional), as disposições (ou os habitus) e as tomadas de posição (as "escolhas" que os agentes sociais fazem nos domínios mais diferentes da prática), deve-se ter o cuidado de não transformar em propriedades intrínsecas ao objeto propriedades que se apresentaram apenas em um determinado momento "em uma dada situação de oferta de bens e práticas possíveis" (BOURDIEU, 1996, p. 17).

O social existe de maneira dupla: nas coisas e nos corpos sendo que é na relação entre o habitus (habitus como esquemas de percepção, apreciação e ação interiorizados) e o campo que se constitui, para Bourdieu (1996), o fundamento de toda prática social. 
Em seu livro Razões práticas: sobre a teoria da ação (1996), o autor chega a afirmar que esta relação "se institui entre duas 'realidades', o habitus e o campo, que são dois modos de existência da história, ou da sociedade, a história feita coisa, instituição objetivada, e a história feita corpo, instituição incorporada" (BOURDIEU, 1996, p. 9). Uma referência em As regras da arte que completa esse pensamento é a seguinte:

\begin{abstract}
A relação entre as posições (no campo) e as disposições (do habitus) tem evidentemente dupla direção. Os habitus, enquanto sistemas de disposições, só se realizam efetivamente em relação com uma estrutura determinada de posições socialmente marcadas (entre outras coisas pelas propriedades sociais de seus ocupantes, através das quais se dão a perceber); mas, ao contrário, é através das disposições, que são elas próprias mais ou menos completamente ajustadas às posições, que se realizam determinadas potencialidades que se achavam inscritas nas posições (BOURDIEU, 2002, p. 299).
\end{abstract}

Para Bourdieu, as mesmas disposições podem conduzir a tomadas de posição estéticas ou políticas diferentes de acordo com: o estado de campo e o grau de institucionalidade do posto correspondente. Por isso, não se pode associar diretamente determinada expressão artística a certos grupos sociais: Se não se pode deduzir as tomadas de posição das disposições, também não se pode relacioná-las diretamente às posições. Em suma, é em um espaço particular que a oposição entre as disposições recebe sua definição completa, isto é, sua particularidade histórica.

As disputas pelo acesso a bens no interior do campo também se caracteriza por um processo de institucionalidade, ou seja, a concentração de capital simbólico por estratégias, como através da adoção de um nome, manifesto, programas, ritos de agregação, entre outros. Estratégias que também contribuem para a formação de grupos e o seu respectivo posicionamento entre posições dominantes e posições de vanguarda. Nesse quesito, em particular, observar as trajetórias construídas, o desencadear das escolhas, é fundamental para compreender como a produção de determinado agente pode estar implicada nesse processo de posicionamento estratégico no interior dos grupos.

A própria herança cultural, em seu estado materializado (nas coisas, nas obras) e em seu estado incorporado (nos corpos, através dos sujeitos e do habitus), só existe e subsiste, efetivamente, nas e pelas lutas que ocorrem no campo, à concorrência entre os agentes (aspecto relacional) que só podem participar do coletivo, na medida em que o incorporaram sob a forma das disposições cognitivas e avaliatórias de um habitus específico. É nesse sentido que, para Bourdieu, a compreensão do funcionamento de um campo de produção cultural e o que aí se produz, implica pensar a "pulsão expressiva", o ato criativo, como parte da lógica específica do campo.

Uma lógica que muitas vezes a História da Arte não revela, conduzida por uma dinâmica própria, mas que se mantém pelo fato se ser reverenciada e obedecida pelos agentes, mesmo aos recém-chegados. A essa lógica específica que impõe uma determinada ordem ao funcionamento do campo que Bourdieu denomina como "instituição transcendente" e que, de algum modo, é operacionalizada por meio das tradições, escolas, convenções, mencionadas por Gombrich (1990). Contudo, a diferença na abordagem de Bourdieu está na noção de habitus associada a esse contexto. Sendo o habitus "estruturas estruturadas predispostas a funcionarem como 
estruturas estruturantes"11 (BOURDIEU, apud ORTIZ, 1983, p. 15), ele tende a assegurar a reprodução das relações objetivas que o geraram.

\section{Considerações finais}

São muitos os elementos e conceitos apresentados por Bourdieu passíveis de serem aplicados à análise e compreensão da questão de estilo em produtos culturais, de modo que um único conceito não poderia explorar com profundidade essa discussão. No entanto, nosso objetivo foi através desse breve percurso, compreender a importância do elemento histórico no âmbito de estudos e discussões relacionadas à questão de estilo, motivados pela percepção de que em muitos estudos a predominância de uma tendência em analisar o estilo da obra a partir de uma perspectiva que privilegia o agente, enquanto autor, em detrimento de uma investigação sobre o contexto, o sistema objetivo, no qual ele está inserido e do qual a sua obra artística é produto.

Em contraponto a essa tendência, que também é hereditária de outras abordagens no campo da crítica da arte, entendemos que a incorporação do elemento histórico é fundamental no sentido de equilibrar a ênfase sobre a figura do agente, trazendo à tona, a consciência de que muitas de suas escolhas - escolhas que terão implicações e repercussões diretas tanto sobre sua obra quanto sobre sua trajetória enquanto artista - estão articuladas com esse contexto maior, o campo no qual o agente está inserido.

Nesse sentido, entre os diversos autores que investigam a questão de estilo, trouxemos um breve panorama sobre as contribuições de Gombrich no campo da História da Arte e nas questões de estilo, justamente por termos partido da compreensão de que seus escritos traziam, ainda que de forma germinal, a necessidade da pesquisa histórica em arte em ir além da imanência da obra. O próprio fato de esse autor abordar a existência de tradições e reconhecer a influência que elas exerciam sobre a formação do artista, já é indício de sua percepção sobre a relatividade de autonomia desse agente.

Em seguida, direcionamos a nossa abordagem para as contribuições de Pierre Bourdieu nas questões de estilo. Inicialmente, fizemos um retrospecto de seu pensamento enquanto sociólogo por entendermos que a sua proposta de Sociologia dos Sistemas Simbólicos consegue lidar com algumas dualidades que se apresentam tanto no campo da Sociologia, em geral, quanto no universo de estudos da Sociologia da Cultura. Uma discussão de fundo epistemológico, cujo resgate é importante no intuito de melhor compreender as soluções que a proposta teórico-metodológica de Bourdieu apresenta para os problemas de investigação. Mesmo com as limitações que porventura essa proposta apresente, ela continua sendo uma alternativa diante do dilema de lidar com as especificidades das obras culturais, sem negligenciar a sua existência como parte de um contexto social.

\footnotetext{
11 Percebe-se nessa noção de habitus associada à "instituição transcendente" a influência do pensamento de Max Weber sobre o pensamento de Bourdieu. Weber a partir da "sociologia da compreensão" tem seu ponto partida no sujeito e define os fenômenos sociais a partir das condutas individuais (sentido da ação é o sentido subjetivo que o ator lhe dá). Para ele, a objetividade social só pode ser apreendida através das ações sociais. Em Weber, o mundo objetivo aparece como uma rede de intersubjetividade resultado de ações dirigidas para o "outro" e que adquirem sentido na medida em que o "outro" compartilha comigo o mesmo mundo social. Tal visão subjetiva na sociologia se contrapunha ao objetivismo de Durkheim. De Weber vem também a ideia de que toda instituição social deve ser reconhecida, aceita como legítima de maneira que os dominados venham aderir ao princípio de sua dominação e se sintam solidários aos dominantes sobre a ordem estabelecida (MORENO, 2013).
} 
Essa mediação que Bourdieu promove entre o agente social e a história, o agente e as estruturas objetivas que constituem a sociedade - e aqui, especificamente, o campo da cultura - são importantes também no processo de busca de um rigor científico para o exame de tais questões. Através de conceitos como habitus, Bourdieu ressalta a necessidade de se considerar a questão do estilo a partir de um sujeito, sim; porém um sujeito situado em um dado momento da história, e situá-lo historicamente permite ao analista/crítico enxergar que, para além de toda inspiração e liberdade que possa haver no ato de criação, o agente está inserido em um contexto de relações que, na medida em que repercutem na sua obra, precisam ser bem compreendidas.

\section{Referências}

BOURDIEU, P. Razões práticas: sobre a teoria da ação. 9ª ed. Trad. Mariza Côrrea. Campinas: Papirus Ed., 1996.

BOURDIEU, P. Esquisse d'une théorie de la pratique. Genève. Lib. Droz, 1972. 163 p.

BOURDIEU, P. A economia das trocas simbólicas. 5a ed. São Paulo: Perspectiva Ed., 1999.

BOURDIEU, P. As regras da arte. Trad. Maria Lúcia Machado. São Paulo: Cia das Letras, 2002.

CHARTIER, R. Pierre Bourdieu e a história. Revista Topoi. Rio de Janeiro, p. 139-182, mar. 2002.

GOMBRICH, E. H. Art and illusion: a study in the psychology of pictorial representation. London: Phaidon Press, 1984. p. 03-32.

GOMBRICH, E. H. Traditión y Creatividad. Anales de Arquitectura, Universidad de Valladolid, Vol. 2, p. 36-49, 1990.

GOMBRICH, E. H. Sobre a interpretação da obra de arte: o quê, o porquê e o como. Tradução de Mônica Eustáquio Fonseca. Cadernos de Arquitetura e Urbanismo, Belo Horizonte, v. 12, n. 13, p. 11-26, dez. 2005.

GUTIÉRREZ, A. B. Análisis y acción: notas sobre Pierre Bourdieu. Runa XXIII. Córdoba: 2002. p. 45-59.

GUTIÉRREZ, A. B. Las practicas sociales: una introducción a Pierre Bourdieu. Córdoba: Ferreyra Editor, 2005. 
MORENO, L. F. As diferentes abordagens do conceito de poder: um estudo comparativo entre Weber, Hannah Arendt, Habermas, Foucault e Bourdieu. VI CONECO - Congresso de Estudantes de Pós-Graduação em Comunicação. UERJ, Rio de Janeiro, outubro de 2013. Disponível em: <http://www.coneco.uff.br/sites/default/ files/institucional/as_diferentes_abordagens_do_conceito_de_poder.pdf>. Acesso em: 10 dez. 2016.

ORTIZ, R. Pierre Bourdieu: sociologia. Trad. Paula Montero e Alícia Auzmendi. São Paulo: Ática Ed., 1983. 